\title{
The Surface Reactivity and Electronic Properties of Small Hydrogenation Fullerene Cages
}

\author{
A. A. El-Barbary ${ }^{1,2}$ \\ ${ }^{1}$ Physics Department, Faculty of Education, Ain Shams University, Cairo, Egypt \\ ${ }^{2}$ Physics Department, Faculty of Science, Jazan University, Jazan, KSA \\ Email: ahla eg@yahoo.co.uk
}

Received 26 May 2015; accepted 5 July 2015; published 8 July 2015

Copyright (C) 2015 by author and Scientific Research Publishing Inc. This work is licensed under the Creative Commons Attribution International License (CC BY). http://creativecommons.org/licenses/by/4.0/

c) (†) Open Access

\begin{abstract}
Density functional theory calculations within the G03W package, with B3LYP exchange functional and applying basis set 6 - $31 \mathrm{G}(\mathrm{d}, \mathrm{p})$ are performed. The surface reactivity and electronic properties of endo-hydrogenation and exo-hydrogenation fullerene cages are studied. It is found that the surface reactivity of mono-hydrogenation fullerene cages is larger than the surface reactivity of un-hydrogenation fullerene cages and the later is larger than the fully hydrogenation fullerene cages. In addition, the calculations show that the endo-hydrogenation fullerene cages possess the same band gaps as the un-hydrogenation fullerene cages, however, the exo-hydrogenation is reduced the band gaps of the un-hydrogenated fullerene cages form $\sim 7 \mathrm{eV}$ to $\sim 5 \mathrm{eV}$.
\end{abstract}

\section{Keywords}

Surface Reactivity, Band Gaps, Small Fullerene Cages, Hydrogenation

\section{Introduction}

The discovery of fullerenes in 1985 was the beginning of a new field of hydrogen storage research [1]. Fullerenes possess a wide range of applications in optical and electronic devices such as solar cells, photovoltaic and electro-optical devices [2], in commercial cosmetic products [3], as well as in biomedicine [4]. Hydrogen bond has been one of the most important elements bonded to the fullerene cages both inter- or intra-molecular [5]-[11]. Fullerene cages possess an outer and an inner surface available for hydrogen storage. Study the surface reactivity of endo-hydrogenation and exo-hydrogenation fullerene cages becomes an attractive research topic. Several hydrogenation techniques of $\mathrm{C}_{60}$ are well described. However, the structures and the symmetry of the small hy- 
drogenation fullerene cages are not understood [12]-[14]. Therefore, the present work is investigated the surface reactivity and the electronic properties of endo-hydrogenation and exo-hydrogenations mall fullerene cages. The hydrogenation is applied with different concentrations and on seven different location sites of small fullerene cages.

\section{Methodology}

All calculations are performed with the DFT as implemented within G03W package [15]-[21], using B3LYP exchange-functional [22] [23] and applying basis set 6 - $31 \mathrm{G} \mathrm{(d,p).} \mathrm{All} \mathrm{obtained} \mathrm{structures} \mathrm{are} \mathrm{fully} \mathrm{optimized.}$ In this work, the energy gap is calculated as $E_{\mathrm{g}}=\mathrm{E}_{\mathrm{LUMO}}-\mathrm{E}_{\mathrm{HOMO}}$ [24], where $\mathrm{E}_{\mathrm{LUMO}}$ is the energy of the lowest unoccupied molecular orbital and $\mathrm{E}_{\mathrm{Hомо}}$ is the energy of the highest occupied molecular orbital. The hydrogen atoms are inserted inside (endo-hydrogenation) and outside (exo-hydrogenation) the fullerene cages. The reactivity and electronic properties of mono-hydrogenation $\left(\mathrm{C}_{n} \mathrm{H}\right)$ and fully hydrogenation $\left(\mathrm{C}_{n} \mathrm{H}_{n}\right.$ and $\left.\mathrm{C}_{n} \mathrm{H}_{n+1}\right)$ fullerene cages are investigated and then compared with un-hydrogenation $\left(\mathrm{C}_{n}\right)$ fullerene cages. There is only one hydrogenation site for $\mathrm{C}_{60}$ and $\mathrm{C}_{20}$ fullerene cages at $65 \%$ site and $55 \%$ site respectively. However, there are four different hydrogenation sites for $\mathrm{C}_{40}$ cages at $55 \%$ site, $5.6 \%$ site, $5 \% \frac{5}{6}$ site and $6 \% 6$ site and there are five different hydrogenation sites for $C_{58}$ cages at $6 \gamma_{6}$ site, $\delta Y_{5}$ site, $5 / 5$ site, $6 \%$ site and $5 \% 5$ site, see Figure 1. The hydrogenation sites have been previously explained in details [13].

For the $5 / 5$ site, each angle of the pentagon is about $108^{\circ}$ and each angle of the heptagon is about $128.57^{\circ}$, so that the cone angle at the vertex of two pentagons and one heptagon is $344.57^{\circ}$. In the $67 / 5$ site, each angle of the hexagon is about $120^{\circ}$, so that the cone angle at vertex of one heptagon, one hexagon and one pentagon is $356.57^{\circ}$. In the $6 \gamma_{6}$ site, the cone angle at the vertex of two hexagons and one heptagon is about $368.57^{\circ}$. For the $55 \%$ site, the cone angle at the vertex of the three pentagons is about $324^{\circ}$. In the $5 \%$ site, the cone angle at the vertex of two pentagons and one hexagon is $336^{\circ}$. For the $65 \%$ site, the cone angle at vertex of two hexagons and one pentagon is $348^{\circ}$. For the $\delta \%$ site, the cone angle at the vertex of three hexagons is equal $360^{\circ}$, forming plane with zero curvature surface.

\section{Results and Discussions}

\subsection{Hydrogenation Influence on the Electronic Properties of Fullerene Cages}

\subsubsection{Electronic Properties of Un- and Mono-Hydrogenation Fullerene Cages}

The band gaps for un-hydrogenation $\left(\mathrm{C}_{n}\right)$ and mono hydrogenation $\left(\mathrm{C}_{n} \mathrm{H}\right)$ cages, from $n=20$ to $n=60$ are calculated and are listed in Table 1 and Table 2. In general, the hydrogenation increases the band gaps of the fullerene cages where $E_{g}\left(C_{n} H\right.$ cages $)>E_{g}\left(C_{n}\right.$ cages $)$. For mono hydrogenation, the band gaps of exo-hydrogenationfullerene cages are smaller than the band gaps of endo-hydrogenation fullerene cages. For exo-hydrogenation, the band gaps from $\mathrm{C}_{20} \mathrm{H}$ to $\mathrm{C}_{44} \mathrm{H}$ cages are in the following order: the $\mathrm{E}_{\mathrm{g}}\left(6 \mathrm{C}_{6} / \mathrm{site}\right)<\mathrm{E}_{\mathrm{g}}(6 / 6$ site $)<\mathrm{E}_{\mathrm{g}}(\mathrm{s} / \mathrm{6} / \mathrm{s}$ site) $<E_{g}\left(55 / 5\right.$ site). The band gaps of fullerene cages from the $\mathrm{C}_{46} \mathrm{H}$ to $\mathrm{C}_{60} \mathrm{H}$ cages are in the order $\mathrm{E}_{\mathrm{g}}(65 \%$ site $)<E_{g}(6 \% \%$ site $)<E_{g}\left(5 \% \%\right.$ site) and for the $C_{58} H$ cage, the $E_{g}(6 \% \%$ site $)<E_{g}(6 \%$ site $)<E_{g}\left(6 \%_{5}\right.$ site $)$ $<\mathrm{E}_{\mathrm{g}}(\mathrm{s}) \mathrm{\sigma} / \mathrm{s}$ site $)<\mathrm{E}_{\mathrm{g}}(\mathrm{V} / \mathrm{s}$ site). The smallest band gap is $0.94 \mathrm{eV}$ for mono exo-hydrogenation C54H fullerene cage at $65 / 6$ site and is less than $1.36 \mathrm{eV}$ of un-hydrogenation $\mathrm{C}_{54}$ fullerene cage.
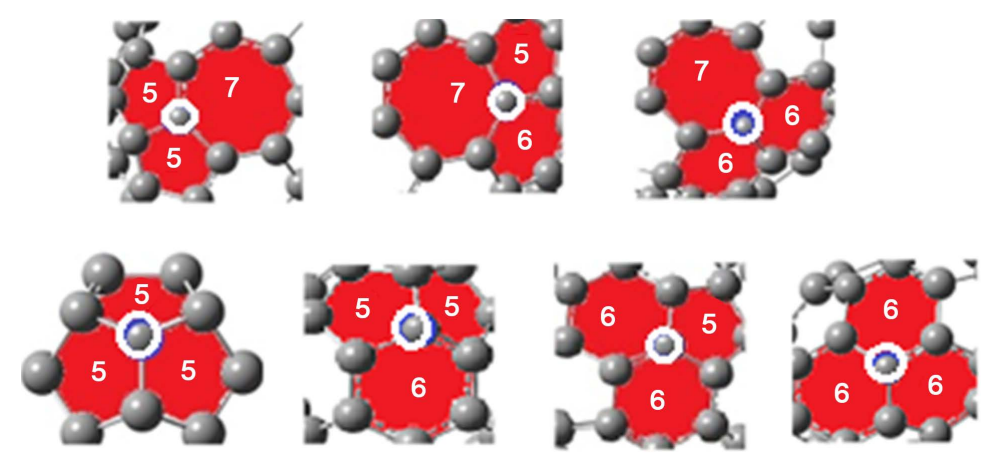

Figure 1. Schematic representations of hydrogenation sites on small fullerene cages. The white circle refers to the location of hydrogenation carbon atom. 
Table 1. The calculated energy gaps $\left(E_{g}\right)$ for un-hydrogenation $\left(C_{n}\right)$ and mono-hydrogenation $\left(C_{n} H\right)$ cages, from $n=20$ to $n$ $=60$. Energy is given by $\mathrm{eV}$.

\begin{tabular}{|c|c|c|c|c|c|c|c|c|c|}
\hline \multirow{3}{*}{\multicolumn{2}{|c|}{$\mathrm{E}_{\mathrm{g}}\left(\mathrm{C}_{\mathrm{n}}\right) / \mathrm{eV}$}} & \multicolumn{8}{|c|}{$\mathrm{E}_{\mathrm{g}}\left(\mathrm{C}_{\mathrm{n}} \mathrm{H}\right) / \mathrm{eV}$} \\
\hline & & \multicolumn{4}{|c|}{ Endo-hydrogenation cages } & \multicolumn{4}{|c|}{ Exo-hydrogenation cages } \\
\hline & & ${ }_{6}^{6} \gamma_{6}$ & ${ }_{6}^{5} / 6$ & $5 \% / 5$ & $55 / 5$ & ${ }_{6}^{6} \%_{6}$ & ${ }_{6}^{5} / 6$ & $5 \%$ & $55 / 5$ \\
\hline $\mathrm{C}_{20}$ & 1.84 & - & - & - & 2.18 & - & - & - & 1.84 \\
\hline $\mathrm{C}_{40}$ & 1.07 & 2.01 & 1.93 & 2.00 & 2.05 & 1.85 & 1.95 & 2.05 & 2.09 \\
\hline $\mathrm{C}_{42}$ & 1.47 & 1.79 & 1.75 & 1.91 & 1.85 & 1.61 & 1.73 & 1.83 & 1.90 \\
\hline $\mathrm{C}_{44}$ & 1.99 & 1.44 & 1.88 & 1.85 & 1.61 & 1.31 & 1.46 & 2.12 & 2.10 \\
\hline $\mathrm{C}_{46}$ & 1.55 & 1.59 & 1.71 & 1.30 & - & 1.46 & 1.25 & 1.40 & - \\
\hline $\mathrm{C}_{48}$ & 1.52 & 1.74 & 1.88 & 2.09 & - & 1.61 & 1.67 & 2.05 & - \\
\hline $\mathrm{C}_{50}$ & 1.57 & 1.78 & 1.59 & 1.98 & - & 1.54 & 1.30 & 1.56 & - \\
\hline $\mathrm{C}_{52}$ & 1.27 & 1.74 & 2.34 & 1.64 & - & 1.42 & 2.24 & 1.88 & - \\
\hline $\mathrm{C}_{54}$ & 1.36 & 1.68 & 1.28 & 2.60 & - & 1.09 & 0.94 & 2.38 & - \\
\hline $\mathrm{C}_{56}$ & 1.71 & 1.33 & 1.16 & 2.11 & - & 1.39 & 1.33 & 2.10 & - \\
\hline $\mathrm{C}_{60}$ & 2.94 & - & 1.84 & - & - & - & 2.05 & - & \\
\hline
\end{tabular}

Table 2. The calculated energy gaps $\left(\mathrm{E}_{\mathfrak{g}}\right)$ for un-hydrogenation $\mathrm{C}_{58}$ and mono-hydrogenation $\mathrm{C}_{58} \mathrm{H}$ fullerene cages. Energy is given by $\mathrm{eV}$.

\begin{tabular}{|c|c|c|c|c|c|c|c|c|c|c|c|}
\hline \multirow{3}{*}{\multicolumn{2}{|c|}{$\mathrm{E}_{\mathrm{g}}\left(\mathrm{C}_{58}\right) / \mathrm{eV}$}} & \multicolumn{10}{|c|}{$\mathrm{E}_{\mathrm{g}}\left(\mathrm{C}_{58} \mathrm{H}\right) / \mathrm{eV}$} \\
\hline & & \multicolumn{5}{|c|}{ Endo-hydrogenation cages } & \multicolumn{5}{|c|}{ Exo-hydrogenation cages } \\
\hline & & ${ }_{6}^{7} / 6$ & $6 Y_{5}$ & $5 / 5$ & $65 \%$ & $5 \%$ & $6 \gamma_{6}$ & $6 / 5$ & $5 / 5$ & $65 \%$ & $5 \%$ \\
\hline $\mathrm{C}_{58}$ & 1.64 & 1.42 & 1.68 & 1.88 & 1.29 & 1.96 & 1.6 & 1.65 & 2.22 & 1.41 & 2.02 \\
\hline
\end{tabular}

\subsubsection{Electronic Properties of Fully Hydrogenation Fullerene Cages}

The band gaps of the $\mathrm{C}_{n} \mathrm{H}_{n}$ and $\mathrm{C}_{n} \mathrm{H}_{n+1}$ fullerene cages, from $n=20$ to $n=60$, are calculated and are listed in Table 3 and Table 4 . The calculated band gaps of $\mathrm{C}_{n} \mathrm{H}_{n}$ fullerene cages are higher than the band gap of $\mathrm{C}_{n}$ fullerene cages. The endo-hydrogenation $\mathrm{C}_{n} \mathrm{H}_{n+1}$ fullerene cages possess the same band gaps as $\mathrm{C}_{n}$ fullerene cages, however exo-hydrogenation $\mathrm{C}_{n} \mathrm{H}_{\mathrm{n}+1}$ fullerene cages is reduced the band gaps of $\mathrm{C}_{\mathrm{n}}$ fullerene cages form $\sim 7 \mathrm{eV}$ to $\sim 5 \mathrm{eV}$.

Figure 2 shows the Mulliken charge populations for $\mathrm{C}_{54}, \mathrm{C}_{54} \mathrm{H}, \mathrm{C}_{54} \mathrm{H}_{54}$ and $\mathrm{C}_{54} \mathrm{H}_{55}$ fullerene cages. For $\mathrm{C}_{54}$ cage the atomic population is almost uniform, about six electrons for carbon atom and one electron for hydrogen atom with small charge transfer about 0.024e, see Figure 2(a). For mono exo-hydrogenation $\mathrm{C}_{54} \mathrm{H}$ cage the charge transfer from hydrogen atom to carbon atom is increased to $\sim 0.4 \mathrm{e}$, see Figures 2(b)-(d). For the fully exo-hydrogenation $\mathrm{C}_{54} \mathrm{H}_{54}$ fullerene cage, the charge transfer from hydrogen atom to carbon atom is about $0.244 \mathrm{e}$, see Figure 2(e), and for exo-hydrogenation $\mathrm{C}_{54} \mathrm{H}_{55}$ fullerene cages is $\sim 0.2 \mathrm{eV}$, see Figures 2(f)-(h).

\subsection{Hydrogenation Influence on the Reactivity Properties of Fullerene Cages}

\subsubsection{Surface Reactivity of Mono Hydrogenated Fullerene Cages}

Going down from $C_{60}$ cage to $C_{20}$ cage by removing the $C_{2}$ units, the number of hexagon rings is reduced and more pentagon rings are created. In other words, the number of hexagon rings is gradually reduced until is reached zero in case of $\mathrm{C}_{20}$ cage. To study the influence of hydrogenation on the surface reactivity of the fullerene cages $C_{n}$, the dipole moments are calculated for $C_{n}$ and $C_{n} H$ cages, from $n=20$ to $n=60$ and are listed in Table 5 and Table 6 . The Dipole moment is the measure of surface reactivity, where the high value of dipole 


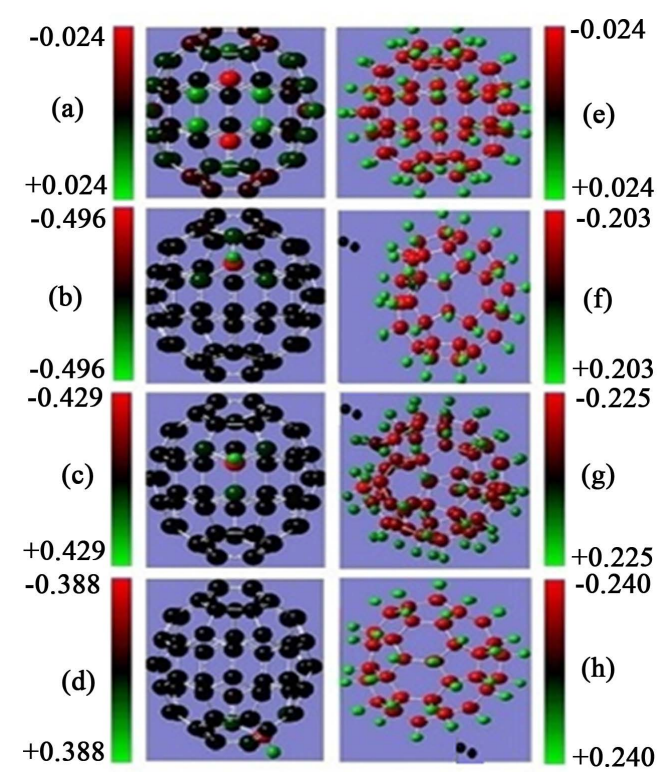

Figure 2. Mulliken charge populations for (a) $\mathrm{C}_{54}$ cage, for $\mathrm{C}_{54} \mathrm{H}$ cages at (b) site, (c) ${ }_{6} \%_{6}$ site, (d) $5 / 6 / 5$ site, for (e) $\mathrm{C}_{54} \mathrm{H}_{54}$ cage, and for $\mathrm{C}_{54} \mathrm{H}_{55}$ cages at (f) ${ }_{6}^{6} \gamma_{6}$ site, (g) $65 / 6$ site, (h) $5 \% / 5$.

Table 3. The calculated energy gaps $\left(E_{g}\right)$ of $C_{n} H_{n}$ and $C_{n} H_{n+1}$ fullerene cages, $n=20$ to $n=60$. Energy is given by eV.

\begin{tabular}{|c|c|c|c|c|c|c|c|c|c|}
\hline & & & & & & $\left.{ }^{n+1}\right) / e V$ & & & \\
\hline$E_{g}\left(C_{n}\right.$ & /eV & & ndo-hy & tion $\mathrm{c}$ & & & Exo-hy & ion ca & \\
\hline & & $6 \%$ & $6 \%_{6}$ & $5 \% / 5$ & $55 / 5$ & $6 \%$ & ${ }_{6}^{5} / 6$ & $5 \%$ & $5 \% / 5$ \\
\hline $\mathrm{C}_{20} \mathrm{H}_{20}$ & 8.53 & - & - & - & 8.64 & - & - & - & 5.86 \\
\hline $\mathrm{C}_{40} \mathrm{H}_{40}$ & 7.46 & 7.91 & 7.91 & 7.91 & 7.91 & 5.74 & 5.22 & 5.36 & 5.28 \\
\hline $\mathrm{C}_{42} \mathrm{H}_{42}$ & 7.43 & 7.82 & 7.82 & 7.82 & 7.82 & 5.77 & 5.19 & 5.19 & 5.31 \\
\hline $\mathrm{C}_{44} \mathrm{H}_{44}$ & 7.37 & 7.71 & 7.70 & 7.71 & 7.71 & 5.72 & 5.05 & 5.27 & 7.38 \\
\hline $\mathrm{C}_{46} \mathrm{H}_{46}$ & 7.35 & 7.63 & 7.58 & 7.63 & - & 5.71 & 5.15 & 5.25 & - \\
\hline $\mathrm{C}_{48} \mathrm{H}_{48}$ & 7.34 & 7.56 & 7.56 & 7.56 & - & 5.72 & 5.12 & 5.24 & - \\
\hline $\mathrm{C}_{50} \mathrm{H}_{50}$ & 7.26 & 7.44 & 7.44 & 7.44 & - & 5.71 & 5.11 & 5.25 & - \\
\hline $\mathrm{C}_{52} \mathrm{H}_{52}$ & 7.26 & 7.41 & 7.41 & 7.41 & - & 5.69 & 5.06 & 5.23 & - \\
\hline $\mathrm{C}_{54} \mathrm{H}_{54}$ & 7.25 & 7.24 & 7.37 & 7.37 & - & 5.78 & 5.05 & 7.26 & - \\
\hline $\mathrm{C}_{56} \mathrm{H}_{56}$ & 7.12 & 7.27 & 6.26 & 7.22 & - & 5.71 & 5.05 & 5.18 & - \\
\hline $\mathrm{C}_{60} \mathrm{H}_{60}$ & 7.28 & - & 7.35 & - & - & - & 5.03 & - & \\
\hline
\end{tabular}

Table 4. The calculated energy gaps $\left(\mathrm{E}_{\mathrm{g}}\right)$ of $\mathrm{C}_{58} \mathrm{H}_{58}$ and $\mathrm{C}_{58} \mathrm{H}_{59}$ fullerene cages. Energy is given by eV.

\begin{tabular}{|c|c|c|c|c|c|c|c|c|c|c|c|}
\hline \multirow{3}{*}{\multicolumn{2}{|c|}{$\mathrm{E}_{\mathrm{g}}\left(\mathrm{C}_{58} \mathrm{H}_{58}\right) / \mathrm{eV}$}} & \multicolumn{10}{|c|}{$\mathrm{E}_{\mathrm{g}}\left(\mathrm{C}_{58} \mathrm{H}_{59}\right) / \mathrm{eV}$} \\
\hline & & \multicolumn{5}{|c|}{ Endo-hydrogenation cages } & \multicolumn{5}{|c|}{ Exo-hydrogenation cages } \\
\hline & & ${ }_{6} Y_{6}$ & ${ }_{6} 7 / 5$ & $5 / 5$ & $65 / 6$ & $5 \% 5$ & ${ }_{6} Y_{6}$ & $8 Y_{5}$ & $5 / 5$ & ${ }_{6}^{5} / 6$ & $5 \%$ \\
\hline $\mathrm{C}_{58} \mathrm{H}_{58}$ & 7.25 & 4.54 & 4.58 & 7.26 & 7.26 & 7.26 & 5.73 & 5.73 & 5.18 & 5.04 & 4.71 \\
\hline
\end{tabular}


Table 5. The calculated dipole moments for un-hydrogenation fullerene $C_{n}$ and mono hydrogenation $C_{n} H$ cages, from $n=20$ to $\mathrm{n}=60$. The dipole moment is given by Debye.

\begin{tabular}{|c|c|c|c|c|c|c|c|c|c|}
\hline & & \multicolumn{8}{|c|}{$\mathrm{C}_{n} \mathrm{H}$} \\
\hline \multicolumn{2}{|c|}{$\mathrm{C}_{\mathrm{n}}$} & \multicolumn{4}{|c|}{ Endo-hydrogenation cages } & \multicolumn{4}{|c|}{ Exo-hydrogenation cages } \\
\hline & & ${ }_{6}^{6} \gamma_{6}$ & ${ }_{6}^{5} / 6$ & $5 \% / 5$ & $5 / 5 / 5$ & ${ }_{6}^{6} \%$ & ${ }_{6}^{5} / 6$ & $5 \%$ & $55 / 5$ \\
\hline $\mathrm{C}_{20}$ & 0.00 & - & - & - & 0.17 & - & - & - & 1.96 \\
\hline $\mathrm{C}_{40}$ & 1.28 & 0.55 & 0.96 & 0.49 & 0.26 & 1.78 & 2.46 & 1.97 & 2.69 \\
\hline $\mathrm{C}_{42}$ & 0.66 & 0.51 & 1.09 & 0.37 & 0.34 & 1.78 & 2.73 & 1.92 & 2.22 \\
\hline $\mathrm{C}_{44}$ & 0.14 & 1.1 & 0.73 & 0.36 & 0.36 & 1.79 & 2.15 & 1.93 & 2.13 \\
\hline $\mathrm{C}_{46}$ & 0.40 & 0.91 & 0.85 & 1.57 & - & 1.98 & 2.9 & 1.97 & - \\
\hline $\mathrm{C}_{48}$ & 0.47 & 1.15 & 0.65 & 0.54 & - & 2.61 & 2.15 & 2.18 & - \\
\hline $\mathrm{C}_{50}$ & 0.49 & 0.66 & 1.58 & 0.76 & - & 1.98 & 2.86 & 2.53 & - \\
\hline $\mathrm{C}_{52}$ & 0.48 & 0.74 & 0.76 & 0.37 & - & 2.15 & 2.04 & 2.12 & - \\
\hline $\mathrm{C}_{54}$ & 0.15 & 0.45 & 2.43 & 0.4 & - & 2.1 & 4.11 & 2.1 & - \\
\hline $\mathrm{C}_{56}$ & 0.16 & 1.06 & 0.37 & 0.67 & - & 1.75 & 1.52 & 2.26 & - \\
\hline $\mathrm{C}_{60}$ & 0.00 & - & 0.24 & - & - & - & 1.70 & - & - \\
\hline
\end{tabular}

Table 6. The calculated dipole moments for un-hydrogenation fullerene $\mathrm{C}_{58}$ and mono hydrogenation $\mathrm{C}_{58} \mathrm{H}$ cages. The dipole moment is given by Debye.

\begin{tabular}{|c|c|c|c|c|c|c|c|c|c|c|c|}
\hline \multirow{3}{*}{\multicolumn{2}{|c|}{$\mathrm{C}_{58}$}} & \multicolumn{10}{|c|}{$\mathrm{C}_{58} \mathrm{H}$} \\
\hline & & \multicolumn{5}{|c|}{ Endo-hydrogenation cages } & \multicolumn{5}{|c|}{ Exo-hydrogenation cages } \\
\hline & & ${ }_{6} 7 \%$ & ${ }_{6} 7 / 5$ & $7 / 5$ & ${ }_{6}^{5} / 6$ & $56 / 5$ & ${ }_{6}>\gamma_{6}$ & ${ }_{6} 7 / 5$ & $7 / 5$ & ${ }_{6}^{5} / 6$ & $5 \%$ \\
\hline $\mathrm{C}_{58}$ & 0.46 & 1.06 & 0.5 & 0.47 & 0.47 & 0.6 & 1.42 & 1.48 & 1.66 & 1.93 & 1.97 \\
\hline
\end{tabular}

moment reflecting the high surface reactivity [25] [26]. First, it is found that the surface reactivity of mono hydrogenation fullerene cages $\left(\mathrm{C}_{n} \mathrm{H}\right)$ is higher than the surface reactivity of un-hydrogenation fullerene cage $\left(\mathrm{C}_{n}\right)$. Second, the surface reactivity for mono exo-hydrogenation fullerene cages is always higher than the surface reactivity of mono endo-hydrogenation fullerene cages. Third, the highest surface reactivity value is 4.11 Debye for the mono exo-hydrogenation $\mathrm{C}_{54} \mathrm{H}$ cage, comparing with $0.15 \mathrm{eV}$ for un-hydrogenation $\mathrm{C}_{54}$ cage. Finally, the $5 / 5$ site is found to be the most reactive site. One can conclude that the surface reactivity of the mono hydrogenation fullerene cages is increased with increasing the number of pentagon-pentagon fusion, agrees with the previous observation [27]. Therefore, the less the cone angle, the larger the curvature and the highest reactive site. Result in the localized carbon atom at three pentagons has the highest reactive site, while the localized carbon atom at three hexagons has the lowest reactive site.

\subsubsection{Surface Reactivity of Fully Hydrogenation Fullerene Cages}

The surface reactivity for the $\mathrm{C}_{n} \mathrm{H}_{n}$ and $\mathrm{C}_{n} \mathrm{H}_{n+1}$ fullerene cages is studied. The dipole moments for $\mathrm{C}_{n} \mathrm{H}_{n}$ and $\mathrm{C}_{n} \mathrm{H}_{n+1}$ fullerene cages from $n=20$ to $n=60$ are calculated and are listed in Table 7 and Table 8 . It is noticed that the surface reactivity for $\left(C_{n} H_{n+1}\right)$ fullerene cage is higher than the surface reactivity for $\left(C_{n} H_{n}\right)$ fullerene cage. Also, the surface reactivity of exo-hydrogenation fullerene cages is always higher than the surface reactivity of endo-hydrogenation fullerene cages. The order of the surface reactivity of endo-hydrogenation $\mathrm{C}_{58} \mathrm{H}_{59}$ cage is at ${ }_{5}^{6} \gamma_{5}$ site $>{ }_{6} 7 / 6$ site $>{ }_{6} 7 / 5$ site $>\gamma_{6}^{5 / 6}$ site $>{ }_{5}^{7 / 5}$ site and for the rest of the $\mathrm{C}_{n} \mathrm{H}_{\mathrm{n}+1}$ fullerene cages is at ${ }_{6} \gamma_{6}$ site $>\quad 5 / 6$ site $>5.6 / 5$ site $>55 / 5$ site. Finally, the highest surface reactivity value is found to be 0.34 Debye for the exo-hydrogenation $\mathrm{C}_{54} \mathrm{H}_{55}$ cage, comparing with $0.04 \mathrm{eV}$ for $\mathrm{C}_{54} \mathrm{H}_{54}$ cage. From Tables 5-8 the dipole moments for $\mathrm{C}_{n}, \mathrm{C}_{n} \mathrm{H}, \mathrm{C}_{n} \mathrm{H}_{n}$ and $\mathrm{C}_{n} \mathrm{H}_{n+1}$ cages, from $n=20$ to $n=60$, are calculated. One can sum- 
Table 7. The calculated dipole moments for $\mathrm{C}_{n} \mathrm{H}_{n}$ and $\mathrm{C}_{n} \mathrm{H}_{n+1}$ cages from $n=20$ to $n=60$. The dipole moment is given by Debye.

\begin{tabular}{|c|c|c|c|c|c|c|c|c|c|}
\hline & & \multicolumn{8}{|c|}{$\mathrm{C}_{n} \mathrm{H}_{\mathrm{n}+1}$} \\
\hline \multicolumn{2}{|c|}{$\mathrm{C}_{n} \mathrm{H}_{\mathrm{n}}$} & \multicolumn{4}{|c|}{ Endo-hydrogenation cages } & \multicolumn{4}{|c|}{ Exo-hydrogenation cages } \\
\hline & & ${ }_{6} \gamma_{6}$ & ${ }_{6}^{5} / 6$ & $54 \% 5$ & $55 / 5$ & ${ }_{6}^{6} \% 6$ & ${ }_{6}^{5} / 6$ & $56 / 5$ & $55 / 5$ \\
\hline $\mathrm{C}_{20} \mathrm{H}_{20}$ & 0.00 & - & - & - & 0.00 & - & - & - & 0.06 \\
\hline $\mathrm{C}_{40} \mathrm{H}_{40}$ & 0.02 & 0.02 & 0.02 & 0.02 & 0.02 & 0.22 & 0.16 & 0.05 & 0.07 \\
\hline $\mathrm{C}_{42} \mathrm{H}_{42}$ & 0.04 & 0.04 & 0.04 & 0.04 & 0.04 & 0.24 & 0.19 & 0.10 & 0.08 \\
\hline $\mathrm{C}_{44} \mathrm{H}_{44}$ & 0.03 & 0.04 & 0.04 & 0.04 & 0.04 & 0.26 & 0.14 & 0.13 & 0.05 \\
\hline $\mathrm{C}_{46} \mathrm{H}_{46}$ & 0.03 & 0.03 & 0.03 & 0.03 & - & 0.27 & 0.18 & 0.09 & - \\
\hline $\mathrm{C}_{48} \mathrm{H}_{48}$ & 0.01 & 0.02 & 0.02 & 0.02 & - & 0.29 & 0.20 & 0.10 & - \\
\hline $\mathrm{C}_{50} \mathrm{H}_{50}$ & 0.03 & 0.03 & 0.03 & 0.03 & - & 0.29 & 0.14 & 0.12 & - \\
\hline $\mathrm{C}_{52} \mathrm{H}_{52}$ & 0.02 & 0.02 & 0.02 & 0.02 & - & 0.28 & 0.11 & 0.07 & - \\
\hline $\mathrm{C}_{54} \mathrm{H}_{54}$ & 0.04 & 0.04 & 0.03 & 0.03 & - & 0.34 & 0.20 & 0.05 & - \\
\hline $\mathrm{C}_{56} \mathrm{H}_{56}$ & 0.05 & 0.05 & 0.08 & 0.06 & - & 0.29 & 0.16 & 0.05 & - \\
\hline $\mathrm{C}_{60} \mathrm{H}_{60}$ & 0.00 & - & 0.05 & - & - & - & 0.13 & - & - \\
\hline
\end{tabular}

Table 8. The calculated dipole moments for $\mathrm{C}_{58} \mathrm{H}_{58}$ and $\mathrm{C}_{58} \mathrm{H}_{59}$ cages. The dipole moment is given by Debye.

\begin{tabular}{|c|c|c|c|c|c|c|c|c|c|c|c|}
\hline \multirow{3}{*}{\multicolumn{2}{|c|}{$\mathrm{C}_{58} \mathrm{H}_{58}$}} & \multicolumn{10}{|c|}{$\mathrm{C}_{58} \mathrm{H}_{59}$} \\
\hline & & \multicolumn{5}{|c|}{ Endo-hydrogenation cages } & \multicolumn{5}{|c|}{ Exo-hydrogenation cages } \\
\hline & & ${ }_{6} \gamma_{6}$ & ${ }_{6} 7 / 5$ & $5 / 5$ & ${ }_{6}^{5} / 6$ & $5 / 6 / 5$ & ${ }_{6} 7 / 6$ & ${ }_{6} 7 / 5$ & ${ }_{5} / 7_{5}$ & ${ }_{6}^{5} / 6$ & $5 \% / 5$ \\
\hline $\mathrm{C}_{58} \mathrm{H}_{58}$ & 0.02 & 0.51 & 0.55 & 0.03 & 0.03 & 0.03 & 0.26 & 0.26 & 0.07 & 0.13 & 0.49 \\
\hline
\end{tabular}

marize that the order of the surface reactivity is for $\mathrm{C}_{n} \mathrm{H}$ cages $>\mathrm{C}_{n}$ cages $>\mathrm{C}_{n} \mathrm{H}_{n+1}$ cages $>\mathrm{C}_{n} \mathrm{H}_{n}$ cages. Also, the most reactive sites are found at $5 / 5 / 5$ site for $\mathrm{C}_{n} \mathrm{H}$ cages and at ${ }_{6} / 6 / 6$ site for $\mathrm{C}_{n} \mathrm{H}_{n+1}$ cages.

\section{Conclusion}

It is found that the surface reactivity order is for $\mathrm{C}_{n} \mathrm{H}$ cages $>\mathrm{C}_{n}$ cages $>\mathrm{C}_{n} \mathrm{H}_{n+1}$ cages $>\mathrm{C}_{n} \mathrm{H}_{n}$ cages. Also, it is noticed that the smallest band gap is $0.94 \mathrm{eV}$ for $\mathrm{C}_{54} \mathrm{H}$ cage when one hydrogen atom is exo-hydrogenatedat the ${ }_{6}^{5} \%$ site, comparing with $1.36 \mathrm{eV}$ of un-hydrogenation $\mathrm{C}_{54}$ cage. In addition, the hydrogen adsorption inside the $\mathrm{C}_{n} \mathrm{H}_{n+1}$ fullerene cages does not affect the band gaps, however the hydrogen adsorption outside $\mathrm{C}_{n} \mathrm{H}_{n+1}$ fullerene cages reduces the band gaps form $\sim 7 \mathrm{eV}$ to $\sim 5 \mathrm{eV}$.

\section{References}

[1] Kroto, H.W., Heath, J.R., O’Brien, S.C., Curl, R.F. and Smalley, R.E. (1985) C60: Buckminsterfullerene. Nature, 318, 162-163. http://dx.doi.org/10.1038/318162a0

[2] Kronholm, D. and Hummelen, J.C. (2007) Fullerene-Based n-Type Semiconductors in Organic Electronics. Material Matters, 2, 16-19.

[3] Xiao, L., Takada, H., Maeda, K., Haramoto, M. and Miwa, N. (2005) Antioxidant Effects of Water-Soluble Fullerene Derivatives against Ultraviolet Ray or Peroxylipid through Their Action of Scavenging the Reactive Oxygen Species in Human Skin Keratinocytes. Biomedicine Pharmacotherapy, 59, 351-358. http://dx.doi.org/10.1016/j.biopha.2005.02.004

[4] Tagmatarchis, N. and Shinohara, H. (2001) Fullerenes in Medicinal Chemistry and Their Biological Applications. Mini-Reviews in Medicinal Chemistry, 1, 339-348. 
[5] Gill, G. and Gill, P. (2009) The Nature of the Hydrogen Bond-Outline of a Comprehensive Hydrogen Bond Theory. Oxford University Press. http://dx.doi.org/10.1093/acprof:oso/9780199558964.001.0001

[6] Desiraju, G.R. and Steiner, T. (1999) The Weak Hydrogen Bond in Structural Chemistry and Biology. Oxford University Press Inc., New York.

[7] Jeffrey, G.A. and Saenger, W. (1991) Hydrogen Bonding in Biological Structures. Springer-Verlag, Berlin. http://dx.doi.org/10.1007/978-3-642-85135-3

[8] Jeffrey, G.A. (1997) An Introduction to Hydrogen Bonding. Oxford University Press, New York.

[9] Grabowski, S.J. (2011) What Is the Covalency of Hydrogen Bonding? Chemical Reviews, 111, 2597. http://dx.doi.org/10.1021/cr800346f

[10] Grabowski, S.J. (2006) Hydrogen Bonding-New Insight. Springer, New York. http://dx.doi.org/10.1007/978-1-4020-4853-1

[11] Desiraju, G.R. (1989) Crystal Engineering. The Design of Organic Solids, Elsevier, Amsterdam.

[12] Briggs, J.B., Montgomery, M.N., Silva, L. and Miller, G.P. (2005) Facile, Scalable, Regioselective Synthesis of $C_{3 \mathrm{v}}$ $\mathrm{C}_{60} \mathrm{H}_{18}$ Using Organic Polyamines. Organic Letters, 7, 5553-5555.

[13] Kintigh, J., Briggs, J., Letourneau, K. and Miller, G.P. (2007) Fulleranes Produced via Efficient Polyamine Hydrogenation of [60]Fullerene, [70]Fullerene and Giant Fullerenes. Journal of Materials Chemistry, 17, 4647-4651. http://dx.doi.org/10.1039/b709354c

[14] Zerenturk, A. and Berbe, S. (2012) Hydrogen Migration on the $\mathrm{C}_{60}$ Fullerene. Solid State Communications, 152, 15221525. http://dx.doi.org/10.1016/j.ssc.2012.06.006

[15] Frisch, M.J., Trucks, G.W., Schlegel, H.B., Scuseria, G.E., Robb, M.A., Cheeseman, J.R., Zakrzewski, V.G., Montgomery, J.A., Stratmann, R.E., Burant, J.C., Dapprich, S., Millam, J.M., Daniels, A.D., Kudin, K.N., Strain, M.C., Farkas, O., Tomasi, J., Barone, V., Cossi, M., Cammi, R., Mennucci, B., Pomelli, C., Adamo, C., Clifford, S., Ochterski, J., Petersson, G.A., Ayala, P.Y., Cui, Q., Morokuma, K., Malick, D.K., Rabuck, A.D., Raghavachari, K., Foresman, J.B., Cioslowski, J., Ortiz, J.V., Stefanov, B.B., Liu, G., Liashenko, A., Piskorz, P., Komaromi, I., Gomperts, R., Martin, R.L., Fox, D.J., Keith, T., Al-Lamham, M.A., Peng, C.Y., Nanayakkara, A., Gonzalez, C., Challacombe, M., Gill, P.M.W., Johnson, B.G., Chen, W., Wong, M.W., Andres, J.L., Head-Gordon, M., Replogle, E.S. and Pople, J.A., Gaussian 2004 (Inc., Wallingford CT).

[16] EL-Barbary, A.A., Lebda, H.I. and Kamel, M.A. (2009) The High Conductivity of Defect Fullerene C 40 Cage. Computational Materials Science, 46, 128-132. http://dx.doi.org/10.1016/j.commatsci.2009.02.034

[17] El-Barbary, A.A., Eid, Kh.M., Kamel, M.A. and Hassan, M.M. (2013) Band Gap Engineering in Short Heteronanotube Segments via Monovacancy Defects. Computational Materials Science, 69, 87-94. http://dx.doi.org/10.1016/j.commatsci.2012.10.035

[18] EL-Barbary, A.A., Ismail, G.H. and Babeer, A.M. (2013) Effect of Monovacancy Defects on Adsorbing of CO, $\mathrm{CO}_{2}$, $\mathrm{NO}$ and $\mathrm{NO}_{2}$ on Carbon Nanotubes: First Principle Calculations. Journal of Surface Engineered Materials and Advanced Technology, 3, 287-294. http://dx.doi.org/10.4236/jsemat.2013.34039

[19] Hindi, A. and EL-Barbary, A.A. (2015) Hydrogen Binding Energy of Halogenated $\mathrm{C}_{40}$ Cage: An Intermediate between Physisorption and Chemisorption. Journal of Molecular Structure, 1080, 169-175. http://dx.doi.org/10.1016/j.molstruc.2014.09.034

[20] EL-Barbary, A.A. (2015) ${ }^{1} \mathrm{H}$ and ${ }^{13} \mathrm{C}$ NMR Chemical Shift Investigations of Hydrogenated Small Fullerene Cages $\mathrm{C}_{\mathrm{n}}$, $\mathrm{C}_{\mathrm{n}} \mathrm{H}, \mathrm{C}_{\mathrm{n}} \mathrm{H}_{\mathrm{n}}$ and $\mathrm{C}_{\mathrm{n}} \mathrm{H}_{\mathrm{n}+1}: \mathrm{n}=20,40,58,60$. Journal of Molecular Structure, 1097, 76-86. http://dx.doi.org/10.1016/j.molstruc.2015.05.015

[21] EL-Barbary, A.A., Eid, Kh.M., Kamel, M.A., Osman, H.M. and Ismail, G.H. (2014) Effect of Tubular Chiralities and Diameters of Single Carbon Nanotubes on Gas Sensing Behavior: A DFT Analysis. Journal of Surface Engineered Materials and Advanced Technology, 4, 66-74. http://dx.doi.org/10.4236/jsemat.2014.42010

[22] Becke, A.D. (1993) Density-Functional Thermochemistry. III. The Role of Exact Exchange. The Journal of Chemical Physics, 98, 5648. http://dx.doi.org/10.1063/1.464913

[23] Becke, A.D. (1998) Density-Functional Exchange-Energy Approximation with Correct Asymptotic Behavior. Physical Review A, 38, 3098-3100. http://dx.doi.org/10.1103/PhysRevA.38.3098

[24] Chang, H., Lee, J.D., Lee, S.M. and Lee, Y.H. (2001) Adsorption of $\mathrm{NH}_{3}$ and $\mathrm{NO}_{2}$ Molecules on Carbon Nanotubes. Applied Physics Letters, 79, 3863. http://dx.doi.org/10.1063/1.1424069

[25] Kotz, J.C., Treichel, P. and Weaver, G.C. (2006) Chemistry and Chemical Reactivity. Thomson Brooks/Cole.

[26] Fay, M.M. (2004) Chemistry Fourth Edition. Pearson Education, Upper Saddle River.

[27] Lin, X., Champness, N.R. and Schröder, M. (2010) Hydrogen, Methane and Carbon Dioxide Adsorption in Metal-Organic Framework Materials. Topics in Current Chemistry, 293, 35-76. http://dx.doi.org/10.1007/128_2009_21 